\title{
Leptomeningeal collaterals are associated with modifiable metabolic risk factors
}

\author{
Bijoy K. Menon, M.D ${ }^{1,2}$, Eric E. Smith, M.D, MPH ${ }^{1,2,3}$, Shelagh B. Coutts, BSc, M.D ${ }^{1,3}$, \\ Donald G. Welsh, PhD ${ }^{3}$, James E. Faber, PhD 4 , Mayank Goyal, M.D ${ }^{1,3}$, Michael D. Hill, M.D, \\ MSc $^{1,2,3}$, Andrew M. Demchuk, M.D ${ }^{1,3}$, Zaheed Damani, MSc ${ }^{2}$, Kyung-Hee Cho, M.D ${ }^{6}$, Hyuk- \\ won Chang, M.D ${ }^{7}$, Jeung-Ho Hong, M.D ${ }^{8}$, and Sung II Sohn, M.D, PhD ${ }^{8}$ \\ ${ }^{1}$ Calgary Stroke Program, Department of Clinical Neurosciences, Hotchkiss Brain Institute, \\ University of Calgary, Canada \\ ${ }^{2}$ Department of Community Health Sciences, University of Calgary \\ ${ }^{3}$ Department of Radiology, University of Calgary \\ ${ }^{4}$ Smooth Muscle Research Group and the Hotchkiss Brain Institute, University of Calgary, \\ Canada \\ ${ }^{5}$ Department of Cell and Molecular Physiology, University of North Carolina \\ ${ }^{6}$ Department of Neurology, Korea University College of Medicine, Seoul, South Korea \\ ${ }^{7}$ Department of Radiology, Dongsan Medical Center, Keimyung University, Daegu, South Korea \\ ${ }^{8}$ Department of Neurology, Dongsan Medical Center, Keimyung University, Daegu, South Korea
}

\section{Abstract}

Objective-We seek to identify potentially modifiable determinants associated with variability in leptomeningeal collateral status in patients with acute ischemic stroke.

Methods-Data are from the Keimyung Stroke Registry. Consecutive patients with M1 segment middle cerebral artery (MCA) \pm intracranial internal carotid artery (ICA) occlusions on baseline CT-angiography (CTA) from May 2004 to July 2009 were included. Baseline and follow-up imaging was analyzed blinded to all clinical information. Two raters assessed leptomeningeal collaterals on baseline CTA by consensus, using a previously validated regional leptomeningeal score (rLMC).

Results-Baseline characteristics $(n=206)$ were: mean age $66.9 \pm 11.6$ years, median baseline NIHSS 14 (IQR 11-20), and median stroke symptom onset to CTA 166 minutes (IQR 96-262), Poor collateral status at baseline (rLMC score 0-10) was seen in 73/206 (35.4\%). On univariate analyses, patients with poor collateral status at baseline were older, hypertensive, had higher white blood cell count, blood glucose, D-dimer, serum uric acid levels, and were more likely to have

Address Correspondence to: Sung,Il Sohn, MD, PhD, Department of Neurology, Dongsan Medical Center, Keimyung University, 56 Dalsung-dong, Jung-gu, Daegu 700-712, South Korea. Tel: +82-53-250-7075, Fax: +82-53-250-7840, sungil.sohn@ gmail.com.

Disclosures

The other authors report no disclosures relevant to the study. 
metabolic syndrome. Multivariable modeling identified metabolic syndrome (OR 3.22 95\% CI 1.69-6.15, p<0.001), hyperuricemia (per $1 \mathrm{mg} / \mathrm{dl}$ OR 1.35 95\% CI 1.12-1.62, $\mathrm{p}<0.01$ ) and older age (per 10 years, OR $1.3495 \%$ CI 1.02-1.77, $\mathrm{p}=0.03$ ) as independent predictors of poor leptomeningeal collateral status at baseline.

Conclusion-Metabolic syndrome, hyperuricemia and age are associated with poor leptomeningeal collateral status in patients with acute ischemic stroke.

\section{Keywords}

Leptomeningeal collaterals; Metabolic syndrome; Hyperuricemia; Ageing; Acute ischemic stroke; Determinants

\section{Introduction}

Leptomeningeal collaterals are pre-existing anastomoses that cross-connect a small number of distal-most arterioles within the crowns of the cerebral artery trees. ${ }^{1,2}$ These collaterals represent potential endogenous bypass vessels capable of maintaining blood flow to brain regions that would otherwise die during an acute ischemic stroke. There is robust evidence from imaging studies among patients with acute ischemic stroke to show that the extent of these collaterals at baseline exhibits substantial variability and that patients with fewer collateral vessels have worse outcomes. ${ }^{3-8}$ The determinants of variability in collateral abundance in patients with acute ischemic stroke are largely unknown. ${ }^{8}$ However, animal studies point to genetic polymorphisms in genes that control formation of the collateral circulation in tissues during development, ${ }^{9-11}$ as well as environmental factors (e.g. ageing, chronic endothelial dysfunction) that are associated with thinning of these collaterals and more severe tissue injury in models of ischemic stroke and peripheral artery disease..$^{8,12}$

Previous pilot studies have shown weak associations between a history of hypertension and poor collaterals, and between use of statins and good collaterals. ${ }^{7,9}$ Age, ischemic preconditioning and presence of cardiovascular risk factors are all hypothesized as determinants of native collateral status. ${ }^{3}, 10,11$ We sought to examine potential determinants of native leptomeningeal collaterals in large cohort of well-studied acute ischemic stroke.

\section{Methods}

Data are from the Keimyung Stroke Registry, an ongoing single center prospective cohort study of patients with acute ischemic stroke presenting to the Keimyung University Hospital in Daegu, South Korea. We included patients presenting with acute ischemic stroke with M1 segment middle cerebral artery (MCA) +/- intracranial internal carotid artery (ICA) occlusions on baseline CT-angio during the time period May 2004 to July 2009 in the study. All patients undergo a non-contrast CT head at admission followed by CT-angiography of the head and neck. Information on demographic and clinical characteristics, medical history, admission physical examination findings including height, weight and waist circumference, and laboratory parameters including complete blood count, blood glucose levels, INR, Creactive protein (CRP), and erythrocyte sedimentation rate (ESR), are collected at baseline. Fasting blood sugar, glycosylated hemoglobin ( $\mathrm{Hb}$ ), serum uric acid (on fasting sample), 
homocysteine, fibrinogen, D-dimer and lipid panel are collected the next morning. Stroke severity is assessed using the National Institute of Health Stroke Scale (NIHSS) at baseline, immediately after treatment, at discharge and at 90 days. Functional status is assessed using the modified Rankin Scale (mRS) at similar time-points. Interval times from stroke symptom onset to presentation in emergency room (ER), imaging, thrombolysis and endovascular procedures are also collected. The local Institutional Review Board approved the study.

In 71 patients who either woke up with or did not have witnessed onset of stroke symptoms, we imputed stroke onset time as midpoint between "last seen normal time" and "time discovered with stroke symptoms". Metabolic syndrome was defined as the presence of 3 or more of the following components: (1) serum triglycerides $<=150 \mathrm{mg} / \mathrm{dL}$ ); (2) HDL cholesterol $<40 \mathrm{mg} / \mathrm{dL}$ for men and $<50 \mathrm{mg} / \mathrm{dL}$ for women; (3) fasting plasma glucose > $110 \mathrm{mg} / \mathrm{dL}$ or use of anti-diabetic medication; (4) blood pressure $>=130 / 85 \mathrm{~mm} \mathrm{Hg}$ or medication use and (5) abdominal obesity. ${ }^{12}$ Abdominal obesity was defined as per the revised Asia-Pacific criteria suggested by the World Health Organization Asia Pacific Region. ${ }^{13,14}$

Standard non-helical NCCT was performed on a multi-slice scanner (Siemens, Forchheim, Germany) using $120 \mathrm{kV}, 170 \mathrm{mAs}$ with 5, mm slice thickness. NCCT was followed by CTA with a helical scan technique. Coverage was from arch to vertex with continuous axial slices parallel to the orbitomeatal line with $0.6 \mathrm{~mm}$ to $1.25 \mathrm{~mm}$ slice thickness. Acquisitions were obtained after a single bolus intravenous contrast injection of 90-120 ml nonionic contrast media into an antecubital vein at 3-5 ml/sec, auto-triggered by appearance of contrast in a region of interest manually placed in the ascending aorta. Baseline and follow-up imaging was analyzed at the imaging core lab of the Seaman MR center and the Calgary Stroke Program. OsiriX version 3.5 (http://www.osirix-viewer.com), an image processing software designed for multi-planar reconstruction and volume rendering was used to reconstruct $2 \mathrm{D}$ multi-planar reconstruction images in axial, coronal, and sagittal planes using 24-mm-thick slabs. Leptomeningeal collaterals were assessed on baseline CT-angio by consensus (BKM, SIS) using the regional leptomeningeal score (rLMC). ${ }^{3}$ This ordinal 20 point score assesses pial arterial enhancement within the total vascular territory supplied by the occluded arterial segment to similar maximal enhancement on the opposite unaffected hemisphere using an ASPECTS based template. ${ }^{3,15}$ The score has demonstrated good inter-rater reliability. ${ }^{3}$ Both readers were blinded to all clinical information and follow-up data at the time of reading the scans.

\section{Statistical Analyses}

Data are reported using conventional descriptive statistics. Potential predictor variables were determined based on causal relevance and availability of data (Table 1). Less than $5 \%$ of data for candidate predictor variables were missing except for glycosylated hemoglobin $(\mathrm{Hb})$; therefore glycosylated $\mathrm{Hb}$ was excluded from multivariable analyses. Otherwise, missing data were imputed to the median value except for height, weight and waist circumference where missing data were imputed to the sex-specific median value. The primary outcome was the rLMC score dichotomized as 0-10 (poor) vs. 11-20 (good). ${ }^{3}$ 
Sensitivity analyses without imputed data were also performed and did not show any difference in results (data not shown). Predictor variables showing significance $(p<0.05)$ in the above analyses were assessed for clinical relevance. Blood glucose and raised white blood cell count that are potentially causal but also hypothesized to increase with increased stress (due to stroke severity and poor collateral status at baseline) were excluded from further analyses. ${ }^{16}$ In addition, multi-collinearity was assessed using Spearman's ranked correlation and Bonferroni's correction for multiple comparisons. Only variables identified as statistically significant in univariate analyses $(\mathrm{p}<0.05)$ and hypothesized as causal were included in multivariable logistic regression modeling. Variables showing correlation $(\mathrm{r} \geq$ 0.25 ) and therefore possibly not independent of each other were not included in the same model. Two-way multiplicative interactions were explored between relevant predictor variables included in the model. Model building was done manually using a combination of backwards elimination and forward selection until a parsimonious model was achieved which includes only predictor variables conventionally significant at $a=0.05$. We tested for an interaction between metabolic syndrome and time from stroke symptom onset to CT time (dichotomized as $\leq 90$ minutes and $>90$ minutes) in predicting poor collateral status, reasoning that if accumulating stroke-related stress increases blood pressure and serum glucose causing false "metabolic syndrome", then an association between apparent "metabolic syndrome" and poor collaterals might be seen in the later time window. Since leptomeningeal collateral status is measured on CT-angiography using an ordered categorical scale (rLMC score), similar models as above were retested using a proportional odds approach where the outcome is analyzed as per 4 different thresholds for poor collateral status (cut 1: rLMC score $0-15$ vs. $16-20$, cut 2 : rLMC score $0-10$ vs. $11-20$ and cut 3: rLMC score 0-5 vs. 6-20). The proportional odds assumption tested using the Brant test was satisfied. $(\mathrm{p}=0.2)$. All $\mathrm{p}$-values are two-sided, with $\mathrm{p}<0.05$ considered statistically significant. Analyses were performed using Stata/SE 12.1 software (Copyright 1985-2011 StataCorp LP).

\section{Results}

During the study period, there were 286 patients with documented anterior circulation occlusions on baseline CT-angiography. After excluding 43 patients with a documented MCA occlusion beyond the M1 MCA segment, 28 patients with isolated ICA without M1 MCA occlusion, 7 patients with simultaneously detected occlusions in the posterior circulation or contralateral ICA territory and 2 patients with poor image quality, 206 patients were included for analyses. The baseline characteristics and outcomes are described in Table 1. Thirty-eight patients $(18.5 \%)$ were treated conservatively, $79(38.4 \%)$ received IV t-PA with or without endovascular therapy and $89(43.2 \%)$ were treated with endovascular therapy alone. Significant correlation was noted between baseline ASPECTS on NCCT and collateral status (Spearman's correlation coefficient $\mathrm{r}=0.54, \mathrm{p}<0.0001$ ).

Patients with poor collateral status at baseline were older, more frequently hypertensive and had higher blood glucose values and higher white blood cell (WBC) count at baseline. They also had higher D-dimer and serum uric acid levels (measured the following morning) and were more likely to be labeled as having metabolic syndrome. (Table 1). We explored the relationship of A) metabolic syndrome, serum uric acid and hypertensive status and B) 
metabolic syndrome, serum uric acid and D-dimer levels in poor collateral status. D-dimer levels are known to be associated with history of hypertension; so these variables were not included in the same model. ${ }^{17}$ Both models A and B included three predictor variables, twoway interactions between these predictor variables and a term testing for joint modification of "metabolic syndrome" by the other two variables. Multivariable modeling using both model A and B identified metabolic syndrome and raised serum uric acid as independent predictors of poor leptomeningeal collateral status at baseline. Hypertensive status and serum D-dimer levels did not modify or confound the association between metabolic syndrome, serum uric acid and the outcome variable (poor collateral status). The final model using forward selection included age in addition to metabolic syndrome and serum uric acid and identified all three as significant independent predictors of poor collateral status (Table 2). Age did not modify or confound the association between metabolic syndrome and raised serum uric acid with poor collateral status. A sensitivity analyses restricted to patients with isolated M1 MCA occlusions showed similar results (Table 3). We also did not find a statistically significant interaction between metabolic syndrome and stroke onset to CT time in a model including serum uric acid and age as the other predictor variables. (Likelihood ratio statistic, $\mathrm{p}=0.99$ ).

In a sensitivity analysis using a proportional odds approach, we tested the final model $\mathrm{C}$ and found similar results across 3 different cuts for the outcome (poor collateral status defined as cut 1: rLMC score $0-15$ vs. $16-20$, cut 2 : rLMC score $0-10$ vs. $11-20$ and cut 3 : rLMC score 0-5 vs. 6-20) (Table 4). The parallel regression assumption for this model was not violated as per Brant's test $(\mathrm{p}=0.2)$ suggesting that metabolic syndrome, raised uric acid and age were independent predictors of poor collateral status (defined in 3 different ways on an ordered categorical scale).

\section{Discussion}

In this study, we identified the presence of metabolic syndrome, hyperuricemia and ageing as independently associated with poor baseline leptomeningeal collateral status among patients presenting with acute ischemic stroke. Variability in native leptomeningeal collateral status can to a large extent be explained by genetic and environmental determinants. Animal studies have been particularly informative, demonstrating the presence of genetic determinants of variation in collateral extent and that natural ageing and experimentally induced endothelial dysfunction cause a reduction in the density of native collaterals in brain and other tissues. ${ }^{10,11,18-20}$ Although studies in the coronary vascular bed in humans have suggested that cardiovascular risk factors including dyslipidemia, hyperglycemia, hypertension, smoking, obesity and ageing may contribute to variability in collateral extent, many of the associations remain uncertain, and causal mechanisms unknown. ${ }^{21,22}$ Studies examining the determinants of variability in native leptomeningeal collateral status in humans have been limited. ${ }^{3,8,9}$ History of hypertension and higher systolic blood pressure on admission have been associated with poor collateral status at baseline, and statin use with good collateral status, in patients presenting with acute ischemic stroke, although the evidence has not been compelling. ${ }^{7,9}$ 
Patients with metabolic syndrome are proposed to have insulin resistance, endothelial dysfunction, decreased circulating adiponectin and heightened expression of plasminogen activator inhibitor-1 (PAI-1) that may negatively influence vascular remodeling and potentially causing microvascular rarefaction and reduction in cerebral arteriolar diameter (external and luminal). ${ }^{23,24}$ Likewise, only a preliminary report addresses this question in experimental studies, finding in a mouse genetic model of chronic metabolic syndrome that the native collateral circulation in brain and hind-limb experiences rarefaction (decline in collateral density and diameter), resulting in more severe tissue loss in models of ischemia. ${ }^{25}$ Ours is the first study to report on an association between metabolic syndrome and poor leptomeningeal collateral status in humans.

There is a growing body of evidence linking raised serum uric acid to cardiovascular risk and increased arteriolar stiffness. ${ }^{26-28}$ Endothelial dysfunction and vascular smooth muscle proliferation are hypothesized as possible mechanisms. ${ }^{27,}{ }^{29}$ Hyperuricemia is known to be associated with hypertension, chronic kidney disease, insulin resistance and the metabolic syndrome. ${ }^{26}$ Controversy still exists as to whether it is a marker of these diseases or a causal factor. ${ }^{26,30}$ Our results suggest that hyperuricemia is associated with poor collateral status after adjusting for age, presence of hypertension, serum D-dimer level and metabolic syndrome. Recent evidence that hyperuricemia is an independent predictor of increased arteriolar stiffness in normal Korean men potentially supports the view that it is causal and reduces collateral status by either causing endothelial dysfunction or decreasing dilatatory capacity of the pial arteries. ${ }^{28}$.

We are also able to confirm findings from animal studies that increasing age results in worsening native collateral status. ${ }^{10,11}$ This association may be mediated by age-associated leptomeningeal collateral rarefaction. ${ }^{10,11}$ Indeed, experimental studies have led to the suggestion that endothelial Nitric Oxide Synthase (eNOS) derived nitric oxide is a maintenance factor for collateral vessels, resulting in their rarefaction with prolonged endothelial dysfunction. ${ }^{11}$

Acute hyperglycemia adversely affects s troke outcome. ${ }^{31}$ It could potentially have a primary role in determining leptomeningeal collateral status. We did find an association between hyperglycemia and poor collateral s tatus on univariate analyses. We did not however have data on glycosylated $\mathrm{Hb}$ in more than $10 \%$ of our patients. Glycosylated $\mathrm{Hb}$ is an indicator of raised blood sugar before stroke symptom onset and is less likely to be affected by stroke severity than blood glucose measured after stroke onset. The current study was unable to distinguish between raised blood glucose prior to $\mathrm{s}$ troke $\mathrm{s}$ ymptom onset that could affect collateral status and raised blood sugar after stroke onset possibly as a result of increased s tress due to the s troke itself. We did not, however, find any association between previous diabetic status and poor collaterals.

Chronic hypertension was not a significant predictor of poor collaterals after adjusting for presence of metabolic syndrome and hyperuricemia. Patients with metabolic syndrome may already have the pathological milieu for hypertension even when there is no clinically detected hypertension. Animal literature suggests that chronic hypertension impairs dilatation of collateral blood vessels in the cerebral circulation. ${ }^{32}$ In a recent study, 
spontaneously hypertensive rats had poor collaterals when compared to normotensive rats; but had increased collateral growth and improved blood flow to ischemic brain after treatment with Angiotensin II AT 1 receptor blockade. ${ }^{33}$ Patients with metabolic syndrome or chronic hypertension could potentially improve collateral status with such treatment. Elevated D-dimer levels are hypothesized to potentiate pro-inflammatory cytokines and possibly cause endothelial dysfunction. ${ }^{34} \mathrm{We}$ did not find any evidence for its association with poor collateral status. We also did not find any role of sex in determining leptomeningeal collateral status. ${ }^{35}$

Our study has limitations. We did not have access to pre-stroke fasting plasma glucose and blood pressure recordings, and therefore used values collected on presentation to the emergency room, instead. These subcomponents of the metabolic syndrome could be affected by the stroke itself. ${ }^{36}$ However, we did not find an increasing prevalence of metabolic syndrome with increasing time from stroke symptom onset, which would be expected if accumulating stroke related stress results in raised plasma glucose and blood pressure. There is, in addition, evidence to suggest that lipid levels remain stable in the first few days of an acute ischemic stroke and are not associated with an acute phase reactant response. ${ }^{37,38}$ Given that metabolic syndrome is only diagnosed if 3 or more of 5 components are present, we think that substantial over-estimation of the metabolic syndrome is unlikely. We cannot entirely exclude the possibility that hyperuricemia could simply be a marker of more severe strokes or, potentially, a neuro-protective response to stroke. ${ }^{30}$ However, our findings are consistent with a growing body of evidence that suggests that hyperuricemia could inhibit collateral function by causing endothelial dysfunction. ${ }^{26-28}$ Our patient cohort is East Asian; as such our findings may only apply to the population we studied. Our study needs to be validated in other patient cohorts. Nonetheless, our study is the largest to date examining determinants of leptomeningeal collateral status in detail.

Our study findings are hypothesis generating and warrant confirmation in independent studies. Metabolic syndrome and hyperuricemia are modifiable determinants of collateral status. Exercise, high fiber and low fat diet, weight loss, metformin, thiazolidinediones, statins, angiotensin receptor blockade, low purine diet, xanthine oxidase inhibitors and uricosuric agents are all potential interventions whose role in improving native collateral status could be studied in future. The knowledge thus gained could focus research on clinical trials and appropriate therapeutic strategies to enhance leptomeningeal collaterals or augment their function either preventively before stroke onset, or in the acute phase after stroke onset.

\section{Acknowledgments}

This research is supported in part by a Faculty of Medicine, University of Calgary team grant. BKM has received a research scholarship from the Heart and Stroke Foundation of Canada for studying determinants of variability in collateral status in humans. SBC, received salary support from the Alberta-Innovates-Health solutions and the Heart and Stroke Foundation of Canada's Distinguished Clinician Scientist award, supported in partnership with the Canadian Institute of Health Research (CIHR), Institute of Circulatory and Respiratory Health and AstraZeneca Canada Inc. MDH is funded by Albeta Innovates Health Solutions and by the Heart \& Stroke Foundation of Alberta/NWT/NU. 


\section{References}

1. Brozici M, van der Zwan A, Hillen B. Anatomy and functionality of leptomeningeal anastomoses: a review. Stroke. Nov; 2003 34(11):2750-62. [PubMed: 14576375]

2. Liebeskind DS. Collateral circulation. Stroke. Sep; 2003 34(9):2279-84. [PubMed: 12881609]

3. Menon BK, Smith EE, Modi J, et al. Regional leptomeningeal score on CT angiography predicts clinical and imaging outcomes in patients with acute anterior circulation occlusions. AJNR American journal of neuroradiology. Oct; 2011 32(9):1640-5. [PubMed: 21799045]

4. Christoforidis GA, Mohammad Y, Kehagias D, Avutu B, Slivka AP. Angiographic assessment of pial collaterals as a prognostic indicator following intra, arterial thrombolysis for acute ischemic stroke. AJNR Am J Neuroradiol. Aug; 2005 26(7):1789-97. [PubMed: 16091531]

5. Miteff F, Levi CR, Bateman GA, Spratt N, McElduff P, Parsons MW. The independent predictive utility of computed tomography angiographic collateral status in acute ischaemic stroke. Brain. Aug; 2009 132(Pt 8):2231-8. [PubMed: 19509116]

6. Maas MB, Lev MH, Ay H, et al. Collateral vessels on CT angiography predict outcome in acute ischemic stroke. Stroke. Sep; 2009 40(9):3001-5. [PubMed: 19590055]

7. Lima FO, Furie KL, Silva GS, et al. The pattern of leptomeningeal collaterals on CT angiography is a strong predictor of long-term functional outcome in stroke patients with large vessel intracranial occlusion. Stroke; a journal of cerebral circulation. Oct; 2010 41(10):2316-22.

8. Menon BK, O’Brien B, Bivard A, et al. Assessment of leptomeningeal collaterals using dynamic CT angiography in patients with acute ischemic stroke. Journal of cerebral blood flow and metabolism : official journal of the International Society of Cerebral Blood Flow and Metabolism. Mar; 2013 33(3):365-71. [PubMed: 23149554]

9. Ovbiagele B, Saver JL, Starkman S, et al. Statin enhancement of collateralization in acute stroke. Neurology. Jun 12; 2007 68(24):2129-31. [PubMed: 17562834]

10. Faber JE, Zhang H, Lassance-Soares RM, et al. Aging causes collateral rarefaction and increased severity of ischemic injury in multiple tissues. Arterioscler Thromb Vasc Biol. Aug; 2011 31(8): 1748-56. [PubMed: 21617137]

11. Wang J, Peng X, Lassance-Soares RM, et al. Aging-induced collateral dysfunction: impaired responsiveness of collaterals and susceptibility to apoptosis via dysfunctional eNOS signaling. $\mathrm{J}$ Cardiovasc Transl Res. Dec; 2011 4(6):779-89. [PubMed: 21538183]

12. Executive Summary of The Third Report of The National Cholesterol Education Program (NCEP) Expert Panel on Detection, Evaluation, And Treatment of High Blood Cholesterol In Adults (Adult Treatment Panel III). JAMA : the journal of the American Medical Association. May 16; 2001 285(19):2486-97. [PubMed: 11368702]

13. Bang OY, Kim JW, Lee JH, et al. Association of the metabolic syndrome with intracranial atherosclerotic stroke. Neurology. Jul 26; 2005 65(2):296-8. [PubMed: 16043803]

14. Iso H, Sato S, Kitamura A, et al. Metabolic syndrome and the risk of ischemic heart disease and stroke among Japanese men and women. Stroke; a journal of cerebral circulation. Jun; 2007 38(6): 1744-51.

15. Barber PA, Demchuk AM, Zhang J, Buchan AM. Validity and reliability of a quantitative computed tomography score in predicting outcome of hyperacute stroke before thrombolytic therapy. ASPECTS Study Group. Alberta Stroke Programme Early CT Score. Lancet. May 13; 2000 355(9216):1670-4. [PubMed: 10905241]

16. O’Neill PA, Davies I, Fullerton KJ, Bennett D. Stress hormone and blood glucose response following acute stroke in the elderly. Stroke; a journal of cerebral circulation. Jul; 1991 22(7):8427.

17. Pieper CF, Rao KM, Currie MS, Harris TB, Cohen HJ. Age, functional status, and racial differences in plasma D-dimer levels in community-dwelling elderly persons. J Gerontol A Biol Sci Med Sci. Nov; 2000 55(11):M649-57. [PubMed: 11078094]

18. Zhang H, Prabhakar P, Sealock R, Faber JE. Wide genetic variation in the native pial collateral circulation is a major determinant of variation in severity of stroke. J Cereb Blood Flow Metab. May; 2010 30(5):923-34. [PubMed: 20125182] 
19. Wang S, Zhang H, Wiltshire T, Sealock R, Faber JE. Genetic dissection of the Canq1 locus governing variation in extent of the collateral circulation. PLoS One. 2012; 7(3):e31910. [PubMed: 22412848]

20. Dai X, Faber JE. Endothelial nitric oxide synthase deficiency causes collateral vessel rarefaction and impairs activation of a cell cycle gene network during arteriogenesis. Circulation research. Jun 25; 2010 106(12):1870-81. [PubMed: 20431061]

21. Teunissen PF, Horrevoets AJ, van Royen N. The coronary collateral circulation: genetic and environmental determinants in experimental models and humans. J Mol Cell Cardiol. Apr; 2012 52(4):897-904. [PubMed: 21959171]

22. de Marchi SF, Gloekler S, Meier P, et al. Determinants of preformed collateral vessels in the human heart without coronary artery disease. Cardiology. 2011; 118(3):198-206. [PubMed: 21701169]

23. Kahn R. Metabolic syndrome: is it a syndrome? Does it matter? Circulation. Apr 3; 2007 115(13): 1806-10. discussion 11. [PubMed: 17404171]

24. Grundy SM, Cleeman JI, Daniels SR, et al. Diagnosis and management of the metabolic syndrome: an American Heart Association/National Heart, Lung, and Blood Institute Scientific Statement. Circulation. Oct 25; 2005 112(17):2735-52. [PubMed: 16157765]

25. Moore SMWM, McFadden WA, Faber JE. Cardiovascular risk factors and endothelial dysfunction cause rarefaction of the collateral circulation and impaired recovery from ischemia. Arterioscler Thromb Vasc Biol. 2012; 32 (5 (suppl)):A 390.

26. Feig DI, Kang DH, Johnson RJ. Uric acid and cardiovascular risk. The New England journal of medicine. Oct 23; 2008 359(17):1811-21. [PubMed: 18946066]

27. Khosla UM, Zharikov S, Finch JL, et al. Hyperuricemia induces endothelial dysfunction. Kidney Int. May; 2005 67(5):1739-42. [PubMed: 15840020]

28. Shin JY, Lee HR, Shim JY. Significance of high-normal serum uric acid level as a risk factor for arterial stiffness in healthy Korean men. Vasc Med. Feb; 2012 17(1):37-43. [PubMed: 22363017]

29. Kanellis J, Watanabe S, Li JH, et al. Uric acid stimulates monocyte chemoattractant protein-1 production in vascular smooth muscle cells via mitogen-activated protein kinase and cyclooxygenase-2. Hypertension. Jun; 2003 41(6):1287-93. [PubMed: 12743010]

30. Amaro S, Urra X, Gomez-Choco M, et al. Uric acid levels are relevant in patients with stroke treated with thrombolysis. Stroke; a journal of cerebral circulation. Jan; 2011 42(1 Suppl):S28-32.

31. Parsons MW, Barber PA, Desmond PM, et al. Acute hyperglycemia adversely affects stroke outcome: a magnetic resonance imaging and spectroscopy study. Annals of neurology. Jul; 2002 52(1):20-8. [PubMed: 12112043]

32. Baumbach GL, Heistad DD. Cerebral circulation in chronic arterial hypertension. Hypertension. Aug; 1988 12(2):89-95. [PubMed: 3044994]

33. Omura-Matsuoka E, Yagita Y, Sasaki T, et al. Hypertension impairs leptomeningeal collateral growth after common carotid artery occlusion: restoration by antihypertensive treatment. J Neurosci Res. Jan; 2011 89(1):108-16. [PubMed: 21046561]

34. Kang DW, Yoo SH, Chun S, et al. Inflammatory and hemostatic biomarkers associated with early recurrent ischemic lesions in acute ischemic stroke. Stroke; a journal of cerebral circulation. May; 2009 40(5):1653-8.

35. Peng X, Wang J, Lassance-Soares RM, et al. Gender differences affect blood flow recovery in a mouse model of hindlimb ischemia. American journal of physiology Heart and circulatory physiology. Jun; 2011 300(6):H2027-34. [PubMed: 21398592]

36. Arenillas JF, Sandoval P, Perez de la Ossa N, et al. The metabolic syndrome is associated with a higher resistance to intravenous thrombolysis for acute ischemic stroke in women than in men. Stroke; a journal of cerebral circulation. Feb; 2009 40(2):344-9.

37. Kargman DE, Tuck C, Berglund L, et al. Lipid and lipoprotein levels remain stable in acute ischemic stroke: the Northern Manhattan Stroke Study. Atherosclerosis. Aug; 1998 139(2):391-9. [PubMed: 9712347]

38. Smith EE, Abdullah AR, Amirfarzan H, Schwamm LH. Serum lipid profile on admission for ischemic stroke: failure to meet National Cholesterol Education Program Adult Treatment Panel (NCEP-ATPIII) guidelines. Neurology. Feb 27; 2007 68(9):660-5. [PubMed: 17325272] 
Table 1

Variables stratified by good vs. poor baseline leptomeningeal collateral status on CT-angio $(n=206) .{ }^{*}$ Lab parameters measured at presentation.

\begin{tabular}{|c|c|c|c|}
\hline & $\begin{array}{c}\text { Good Leptomeningeal } \\
\text { Collaterals } \\
\text { ( rLMC score 11-20) }(\mathrm{n}=133)\end{array}$ & $\begin{array}{c}\text { Poor Leptomeningeal } \\
\text { Collaterals (rLMC score 0-10) } \\
(n=73)\end{array}$ & p value \\
\hline \multicolumn{4}{|l|}{ Demographics } \\
\hline Age (in yrs, mean+/- SD) & $65.6+/-12.2$ & $69.1+/-10.1$ & 0.04 \\
\hline Sex (male, $\%)$ & $54.90 \%$ & $47.90 \%$ & 0.38 \\
\hline \multicolumn{4}{|l|}{ Baseline Clinical Measurements } \\
\hline Height in $\mathrm{cm}$ (IQR) & $163(14)$ & $162.5(13)$ & 0.84 \\
\hline Weight in $\mathrm{Kg}$ (IQR) & $60(11)$ & $60(13)$ & 0.34 \\
\hline Waist in $\mathrm{cm}(\mathrm{IQR})$ & $82(12)$ & $81(23)$ & 0.96 \\
\hline Body Mass Index in kg/m2 (IQR) & $22.5+/-4$ & $22.9+/-3.02$ & 0.38 \\
\hline Systolic Blood Pressure +/- SD (mmHg) & $136.5+/-27.2$ & $143.1+/-29.2$ & 0.11 \\
\hline $\begin{array}{l}\text { Diastolic Blood Pressure +/- SD (mm } \\
\mathrm{Hg})\end{array}$ & $82.7+/-12.8$ & $83.6+/-13.5$ & 0.63 \\
\hline Temperature (IQR) (celsius) & $36.4(0.6)$ & $36.2(0.5)$ & 0.01 \\
\hline Onset to CT time (median, IQR) (mins) & $137.5(147.5)$ & $136.0(119)$ & 0.19 \\
\hline \multicolumn{4}{|l|}{ Pre-morbid Risk Factors } \\
\hline Hypertension (\%) & $47.4 \%$ & $64.4 \%$ & 0.02 \\
\hline Coronary arterial disease $(\%)$ & $34.2 \%$ & $24.8 \%$ & 0.19 \\
\hline Diabetes mellitus (\%) & $27 \%$ & $37.0 \%$ & 0.15 \\
\hline Smoking (\%) & $34.1 \%$ & $31.5 \%$ & 0.41 \\
\hline Previous stroke/TIA (\%) & $18.6 \%$ & $23.3 \%$ & 0.27 \\
\hline \multicolumn{4}{|l|}{ Laboratory Studies } \\
\hline Blood Glucose +/-SD (mg/dL)* & $133.1+/-48.1$ & $164.5+/-95.5$ & $<0.01$ \\
\hline Hemoglobin in $\mathrm{g} / \mathrm{dL} *(\mathrm{IQR})$ & $13.2(2.1)$ & $13.7(2.2)$ & 0.08 \\
\hline Hematocrit $(\%)^{*}$ & $38.4(7.3)$ & $40.3(6.2)$ & 0.07 \\
\hline WBC count in cells/mL* (IQR) & $7780(3280)$ & $8460(3940)$ & 0.02 \\
\hline Platelet count in cells per mL* (IQR) & $235000(93,000)$ & $230000(72,000)$ & 0.27 \\
\hline ESR mm/hr* (IQR) & $11(14)$ & $12(17)$ & 0.98 \\
\hline CRP in mg/L* (IQR) & $0.38(1.01)$ & $0.38(1.17)$ & 0.85 \\
\hline INR IU* (IQR) & $1(0.12)$ & $1(0.12)$ & 0.29 \\
\hline D-dimer mcg/mL (IQR) & $1(2.1)$ & $2.25(4.2)$ & $<0.01$ \\
\hline Serum Fibrinogen mg/dL (IQR) & $253(103)$ & $268(99)$ & 0.18 \\
\hline Serum Homocysteine $\mu \mathrm{mol} / \mathrm{L}$ (IQR) & $10.52(5.7)$ & $11.02(5.7)$ & 0.46 \\
\hline Serum Uric acid mg/dL (IQR) & $4.8(2.5)$ & $5.3(2.2)$ & $<0.01$ \\
\hline Total Cholesterol mg/dL (IQR) & $175(64)$ & $180(42)$ & 0.38 \\
\hline Triglycerides mg/dL (IQR) & $83.8(59.1)$ & $90.6(47.5)$ & 0.15 \\
\hline HDL-C mg/dL (IQR) & $45.3(14.5)$ & $46.1(13.9)$ & 0.73 \\
\hline LDL-C mg/dL (IQR) & $103.5(52.3)$ & $117.3(29.8)$ & 0.09 \\
\hline Metabolic Syndrome & $21.50 \%$ & $46.60 \%$ & $<0.01$ \\
\hline
\end{tabular}




\begin{tabular}{lccc}
\hline & $\begin{array}{c}\text { Good Leptomeningeal } \\
\text { Collaterals } \\
(\mathbf{r L M C} \text { score 11-20) }(\mathbf{n = 1 3 3})\end{array}$ & $\begin{array}{c}\text { Poor Leptomeningeal } \\
\text { Collaterals (rLMC score 0-10) } \\
(\mathbf{n = 7 3})\end{array}$ & p value \\
\hline $\begin{array}{l}\text { Outcomes } \\
\text { mRS 0-2 at } 90 \text { days }\end{array}$ & $40.60 \%$ & $19.20 \%$ & $<0.01$ \\
\hline
\end{tabular}

rLMC score indicates regional leptomeningeal collateral score; IQR, Interquartile Range; SD, Standard Deviation; WBC, White Blood Cell; mL, milliliter; ESR, Erythrocyte sedimentation rate; CRP, C-reactive protein; INR, International Normalized Ratio; mcg, microgram; mg, milligram; dL, deciliter; $\mu \mathrm{mol}$, micro-mole; L, liter; HDL, High density lipoprotein; LDL, Low density lipoprotein; mRS, modified Rankin Scale. 


\section{Table 2}

Final model predicting poor leptomeningeal collateral status (rLMC score 0-10) using logistic regression and forward selection. ( $\mathrm{N}=206)$

\begin{tabular}{lcccc}
\hline Variable & Odds Ratio & $\begin{array}{c}\text { Lower 95\% } \\
\text { of OR }\end{array}$ & $\begin{array}{c}\text { Upper 95\% } \\
\text { of OR }\end{array}$ & p value \\
\hline Metabolic Syndrome & 3.22 & 1.69 & 6.15 & $<0.001$ \\
$\begin{array}{l}\text { Serum Uric Acid (per 1 } \\
\text { mg/dL) }\end{array}$ & 1.35 & 1.12 & 1.62 & 0.001 \\
Age (per 10 years) & 1.34 & 1.02 & 1.77 & 0.033 \\
\hline
\end{tabular}




\section{Table 3}

Final model (Sensitivity Analyses) predicting poor leptomeningeal collateral status (rLMC score 0-10) using logistic regression and forward selection in the subgroup of patients with isolated M1 MCA occlusions. $(\mathrm{N}=116)$

\begin{tabular}{llccc}
\hline Variable & Odds Ratio & $\begin{array}{c}\text { Lower 95\% } \\
\text { of of OR }\end{array}$ & $\begin{array}{c}\text { Upper 95\% } \\
\text { of OR }\end{array}$ & p value \\
\hline Metabolic Syndrome & 2.17 & 1.24 & 5.21 & 0.02 \\
$\begin{array}{l}\text { Serum Uric Acid (per 1 } \\
\text { mg/dL) }\end{array}$ & 1.43 & 1.08 & 1.88 & 0.01 \\
Age (per 10 years) & 1.48 & 1.02 & 2.23 & 0.04 \\
\hline
\end{tabular}




\section{Table 4}

Proportional odds model predicting poor leptomeningeal collateral status (cut 1: rLMC score 0-15 vs. 16-20, cut 2: rLMC score $0-10$ vs. 11-20 and cut 3: rLMC score 0-5 vs. 6-20). Brant test $\mathrm{p}$ value $=0.16$ suggesting that the parallel regression assumption has not been violated for this model. $(\mathrm{N}=206)$

\begin{tabular}{lcccc}
\hline Variable & $\begin{array}{c}\text { Odds } \\
\text { Ratio }\end{array}$ & $\begin{array}{c}\text { Lower } \\
\mathbf{9 5 \%} \text { of } \\
\text { OR }\end{array}$ & $\begin{array}{c}\text { Upper } \\
\mathbf{9 5 \%} \text { of } \\
\text { OR }\end{array}$ & p value \\
\hline $\begin{array}{l}\text { Metabolic Syndrome } \\
\begin{array}{l}\text { Serum Uric Acid (per 1 } \\
\text { mg/dL) }\end{array}\end{array}$ & 2.27 & 1.25 & 4.11 & 0.007 \\
\begin{tabular}{l} 
Age (per 10 years) \\
\hline$\beta_{0}$ coefficients with 95\% CI for poor collaterals at each pre-specified cut
\end{tabular} & 1.25 & 1.08 & 1.46 & 0.003 \\
\hline /cut 1 & 1.51 & 1.19 & 1.92 & 0.002 \\
/cut 2 & 2.6 & 0.84 & 4.37 & N/A \\
/cut 3 & 4.89 & 3.01 & 6.76 & N/A \\
\hline
\end{tabular}

